DOI: http://doi.org/10.52716/jprs.v11i2.496

\title{
The Influence of Glass Fiber and Milled Glass Fiber on the Performance of Iraqi Oil Well Cement
}

\author{
Amel Habeeb Assi ${ }^{1, *}$, Faleh H. M. Almahdawi ${ }^{2}$, Qasim Abdulridha Khalti ${ }^{3}$ \\ ${ }^{1,2}$ Petroleum Engineering Department, College of Engineering, University of Baghdad, Baghdad, \\ Iraq. \\ ${ }^{3}$ Petroleum Research and Development Center \\ 1,*Corresponding Author E-mail: zahraa_z91@yahoo.com, \\ ${ }^{2}$ E-mail: dr.f.h.m.almahdawi@ coeng.uobaghdad.edu.iq \\ ${ }^{3}$ E-mail: qassim1971@yahoo.com
}

Received 12/10/2020, Accepted 3/12/2020, Published 20/6/2021

This work is licensed under a Creative Commons Attribution 4.0 International License.

\begin{abstract}
$\underline{\text { Abstract }}$
The reinforced fiberglass in cement slurry reflects the effect on its properties compared to usual additives. Fiberglass is typically used in cement slurry design for one or another of the following goals: (Earth earthquake, bearing storage, and with differential stresses, to enhance cement durability and increase its compressive strength). The main goal is to use glass fiber and ground fiberglass to improve the tensile strength and moderate compressive strength significantly. On the other hand, the use of glass fibers led to a slight increase in the value of thickening time, which is a desirable effect. Eleven glass fiber samples and milled glass fiber were used to show these materials' effect on Iraqi cement with $(0.125,0.25,0.5,0.75,1$, and 2$) \%$ of cement weight. Those tests used to study cement slurry's following properties were compressive strength, thickening time, rheology properties of free water, filtering, and density. These evaluations showed that slurries with less than $1 \%$ fiber content gave a higher compressive strength than a sample containing more than $1 \%$ glass fiber. However, the slurry mixed with equal or less than $1 \%$ milled glass fiber is higher compressive than the sample mixed with more than $1 \%$ milled glass fiber. So the optimal concentration for glass fiber is less than $1 \%$ by weight of cement (BWOC); either for milled glass fiber, it is less or equal to $1 \%$ BWOC. Both materials contributed to increasing the
\end{abstract}




\section{Journal of Petroleum Research and Studies}

Open Access

No. 31, June 2021, pp.30-48

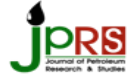

P- ISSN: 2220-5381

E- ISSN: 2710-1096

compressive strength of the cement. However, attention must be paid to the ideal concentration that should be added during the cement slurry preparation because if we use these two materials carelessly for the ideal concentration, this leads to the collapse and bombardment of the resistance of the cement rock. In other words, the collapse of cement resistance and causing problems during the cementing process.

Keywords: Glass Fiber, Cement, Slurry, Compressive strength, Thickening time.

\section{Introduction:}

Each casing should be cemented base on specific cement program to get well bore support and perfect zonal isolation to avoid down hole blowout i.e., fluid flow from one permeable zone to another.

After the casing reach to its setting depth, a series of fluid will be pumped inside casing and coming back to the annulus during cement operation [1]. Due to the increasing need to use materials to design a good cement slurry, many experiments have been carried out to design a cement slurry using fiber to obtain excellent performance during the cementing job [2].

The compressive strength of cement is affected by the materials used. Cement is a major component in oil and gas drilling operations used to maintain a borehole's integrity by preventing the movements of formation fluids through the annular space and outside the casing [3]. Iraqi oil well cement class $G$ has been used recently to cement the oil and gas wells. It was found that this type of cement did not meet the requirements of most drilling wells since it failed in formation-casing bonding, which attributed to long hardening time with low compressive strength.

Consequently, many problems have resulted, additional cost and time consuming of the repair process. Laboratory tests of set cement indicated that this type did not meet the American Petroleum Institute (API). Some oxides in cement, for instance, $\mathrm{MgO}, \mathrm{CaO}$, and $\mathrm{SO}_{3}$ may reason for expansive reactions with the time that principal to a reduction 


\section{Journal of Petroleum Research and Studies}

Open Access

No. 31, June 2021, pp.30-48

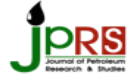

P- ISSN: 2220-5381

E- ISSN: 2710-1096

in cement compressive strength. If those oxides were found in high percentages, they would lead to crucial destruction of cement. on the other hand, the percentage of $\mathrm{CaO}$ in Iraqi cement is (69\%), which is too high. $\mathrm{SO}_{3}$ in Iraqi cement about $3.072 \%$. The present study was also carried out to investigate the combined effect of those oxides contents in cement on cement's compressive strength.

The increase in $\mathrm{MgO}$ content results in a decrease in the compressive strength and a reduction in the cement durability. Generally, Iraqi cement is jelly cement, so it fast thickening time, also it has low compressive strength. If it still in this statement, this type of cement gives bad cementing between casing and layers. Iraqi cement is the low percentage of silica, which is about $18.63 \%$ depending on X-ray fluorescence analysis (XRF).

The high content of silica in glass fibers and milled glass fibers is considered one of the materials rich in silica, where the percentage of silica is about $55 \%$ and $54 \%$ in both materials, respectively. Thus, the use of both materials above is the appropriate solution to the Iraqi cement problem. The investigation of fiberglass use as a strengthening of cement was first directed in Russia in the 1940s and was then presented to the world's industry in the early 1970s in the United Kingdom. The fibers retain loads while the cement maintains the fiber reinforcement location and defends the fibers from the adjacent environment's destruction [4].

The use of waste glass thattypically obtained from recycling of container glass, has been widely investigated in Portland cement, both as a crushed granular aggregate material and in a finely ground form as a cement replacement material [5]. However, glass waste is derived from other waste forms such as windowpanes, fiberglass, abrasive material. Some of the cement types are weak in tension and has moderately low compressive strength and little resistance to impact loading. Investigators have been transmission experiments to overcome these bad aspects of cement by using numerous 


\section{Journal of Petroleum Research and Studies}

Open Access

No. 31, June 2021, pp.30-48

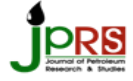

P- ISSN: 2220-5381

E- ISSN: 2710-1096

sort of fiber which offer a suitable and practical means of attaining developments in many of the engineering belongings of the material, for instance, fracture toughness [6]. Glass fibers are one example of those materials of this kind. One of the important uses of fiberglass material in the petroleum industry is to prevent the loss of the drilling fluid cycle due to the inert substantial used in the slurry additive does not distress specified slurry cement properties, it can supply the slurry through the mixing tub period. It allows for the glass fibers to be used only in the share of the slurry selected to be pushed downhole, where losses are predictable to happen [7].

As soon as dispersed in the cement slurry, the fibers generate a physical network that, when placed crossways loss zones, lets the cement bridge-off these zones, subsequent in recommencing the cement's circulation during management [8]. However, in this study, another benefit was found for glass fiber and its usefulness as one of the materials that prevent the loss of the drilling fluid cycle, increasing cement rock's compressive strength due to its high silica content. Milled fiber is made by cutting A.R.G. (artificial refined glass) fiber shortly into the length of dozens to several hundred $\mu \mathrm{m}$. Its high alkali and heat resistance are used as a viscosity modifier for special paint [9]. Glass Fiber contains a high concentration of zirconia and has acid resistance and alkaline resistance high levels. It is mainly used to reinforce Glass Fiber Reinforced Concrete (G.R.C.) and Calcium Silicate products [10], and and as crack control material for normal concrete and cement slurry.

For more than 40 years, it has been widely applied in construction and civil engineering. Glass can be turned into micron-sized fibers. These fibers are also known as milled glass [11]. These milled glass fibers have been used for decades within the construction industry to insulate houses' walls and roofs [12]. Construction manufacturing has currently originated a new use for milled glass as a composite material in the recycled collective and high-performance cement [13]. In addition to the above uses for this substance, this research will determine the extent of its effect on cement slurry. This 


\section{Journal of Petroleum Research and Studies}

Open Access

No. 31, June 2021, pp.30-48

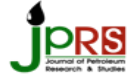

P- ISSN: 2220-5381

E- ISSN: 2710-1096

work aims to describe and evaluate the performance of Iraqi cement produced in Babel (Domestic Cement), according to the American Petroleum Institute (API), using fiberglass and milled fiberglass. Also, finding the effect of the two above materials on cement properties and knowing the optimal amount of addition to those materials. This analysis is an effort to improve the physical and chemical properties of locally made cement in Iraq to use Iraqi cement to support functional operation in our field as an alternative to foreign cement.

\section{Experimental Work}

\subsection{Materials:}

2.1.1 Cement: The cement used in this study is produced in recent times by the Babil cement plant (oil well cement, Class G, H.S.R.). This type of cement is also used in cementing jobs in east Baghdad field /southern zone, as shown in Figure (1 a).

2.1.2 Water: Along with the experiment, tap water was used to prepare a slurry mixture. Water is essential to ensure a continuous hydration process. According to API specification, the water should be free from sensitive elements like ions and impurities to assure the cement's quality.

2.1.3 Fiber Glass: ASTM standard defines glass, in general terms, as: "an inorganic product of fusion which has cooled to a rigid condition without crystallizing. The last two words are particularly important because they relate to the principle morphological of glass, i.e. (its amorphous nature). Compatible with most cementing systems and additives, glass fiber is added during the cementing process. Is considered as a new building material, which has different properties than those of typical slurry. Glass fiber reinforced concrete or slurry is usual for one or more of the following reasons: 


\section{Journal of Petroleum Research and Studies}

Open Access

No. 31, June 2021, pp.30-48

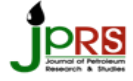

P- ISSN: 2220-5381

E- ISSN: 2710-1096

Structural such as (loading, fire, and earthquake), handling such as (to withstand stocking, transport, and erection stress), and shrinkage (to withstand differential stresses). Glass fibers were found to improve the tensile strength, flexural strength significantly, and they were little affected on the compressive strength. Reinforcing cement by mixing in fiber is one method for preventing cracks from happening in line for drying shrinkage [14]. Fiberglass helps to eliminate losses during cementing operations, reducing the need for costly remedial squeezing actions. Also, this material helps avoid cement fallback and decreases excess cement revenues, thus lessening disposal costs. The most important feature of this material, is that, it can be added to the cement slurry, does not have an emotional impact on cement properties, and wellmatched with furthermost cementing structures and additives, as shown in Fig. 1b. Once dispersed in the slurry, the fibers form a network structure laid down across loss zones, allowing the cement to bridge-off and resume circulation. They can be readily dispersed in water-based fluids such as cement, as shown in Figure (2) [15].

2.1.4 Milled Glass Fiber: It is very fine fiberglass used to promote adhesion when applying it as a special additive for cement slurry design. This material consists of 54.4 wt. $\% \mathrm{SiO}_{2}$ and has a striking effect to enhance and increase cement bond due to the high percentage of $\mathrm{SiO}_{2}$ that has been present in this material, that dominated the total bond behaviorGlass can be milled to make micron-sized fibers, and the most commonly used is fiberglass. Fiberglass is made of a number of these nanofibers mixed with a polymer. These single glass fibers have similar properties and advantages to polymers and carbon fibers. Milled glass fibers are much cheaper to contribute to creating a less brittle structure when used with other materials. The properties of milled fiberglass are in line with strength applications to create a lightweight and more stable material than pre-composites [16], as shown in Figure (1c). The chemical composition of Iraqi cement, fiberglass, and milled glass fiber in detail, depending on X-ray Fluorescence Analysis (XRF), is illustrated in Table (1). 
Table (1) The Chemical Composition of Iraqi Cement, Fiberglass, and Milled Glass Fiber

\begin{tabular}{cccc}
\hline Compound & $\begin{array}{c}\text { Iraqi } \\
\text { Cement } \% \\
\text { by wt. }\end{array}$ & Fiberglass\% & Milled Glass Fiber\% \\
\hline $\mathrm{SiO}_{2}$ & 18.63 & 55 & 54 \\
$\mathrm{Al}_{2} \mathrm{O}_{3}$ & 2.996 & 13.9 & 13 \\
$\mathrm{Fe}_{2} \mathrm{O}_{3}$ & 5.587 & 0.23 & 0.75 \\
$\mathrm{CaO}$ & 69.49 & 22.9 & 17 \\
$\mathrm{MgO}$ & 1.777 & 0.34 & 6 \\
$\mathrm{~K}_{2} \mathrm{O}$ & 0.1703 & 0.29 & - \\
$\mathrm{Na}_{2} \mathrm{O}$ & 1.607 & 0.79 & 1 \\
$\mathrm{SO}_{3}$ & 3.072 & - & - \\
$\mathrm{B}_{2} \mathrm{O}_{3}$ & - & 6.35 & 6 \\
\hline
\end{tabular}

2.1.5 Super Plasticizer: The superplasticizer that used in this paper is Glenium C380. It is a novel superplasticizer appropriate for reducing the thickening time of slurry and increasing compressive strength. Unique its benefits are that it can develop both early and final compressive strength. Furthermore, slump preservation and slurry workability also improved by using Glenium C 380, if associated with an old-style superplasticizer. Superplasticizer (S.P.) is essential to improve the workability and to set time of slurry. Also, aid in decreasing shrinkage and thermal cracking. The additives levels of S.P. should be less than $15 \%$ of water to slow the setting rate of the slurry while keeping the flowing properties of cement slurry [16], as shown in Figure (1d). 

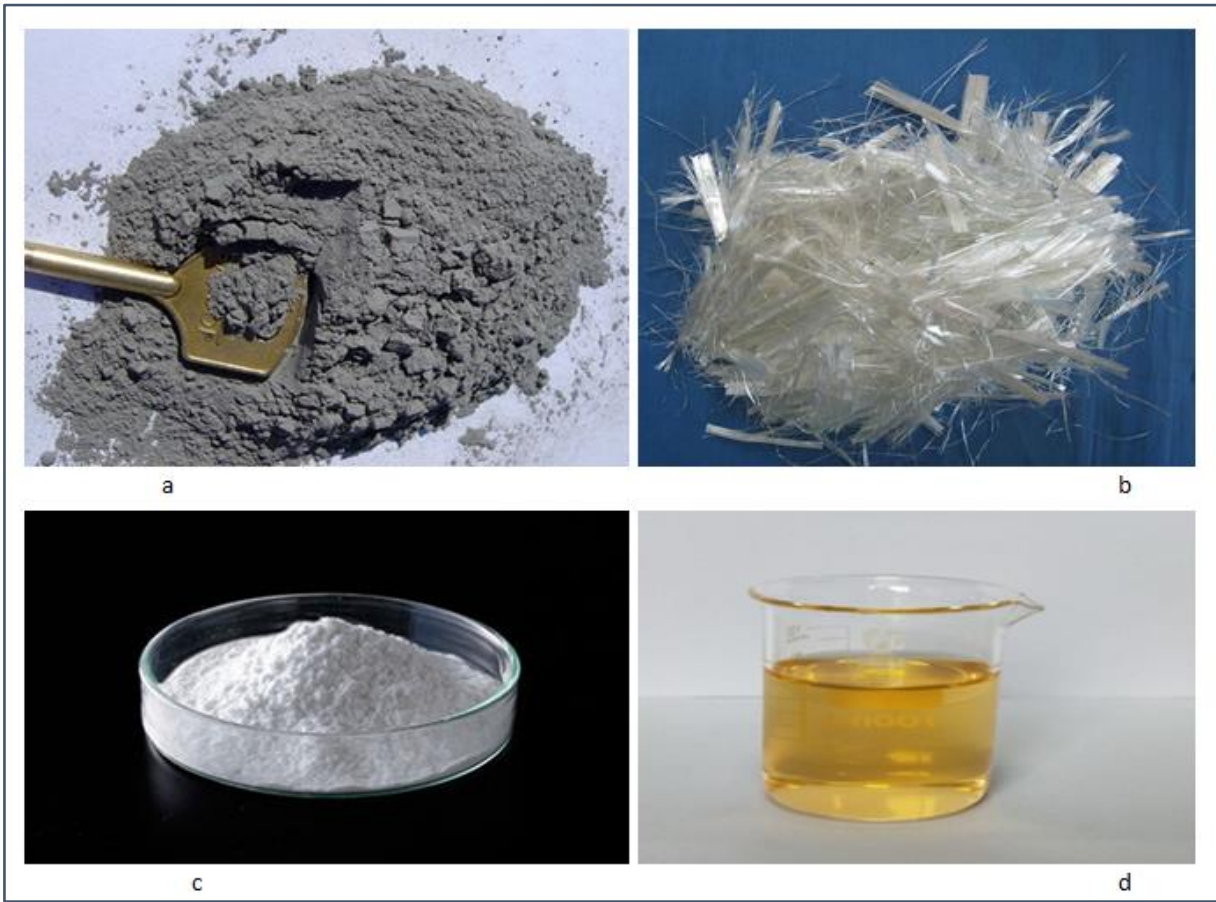

C

Fig. (1) The Used Materials are: (a) Iraqi Cement, (b) Fiberglass, (c) Milled Fiberglass, (d) Superplasticizer Structuro 335
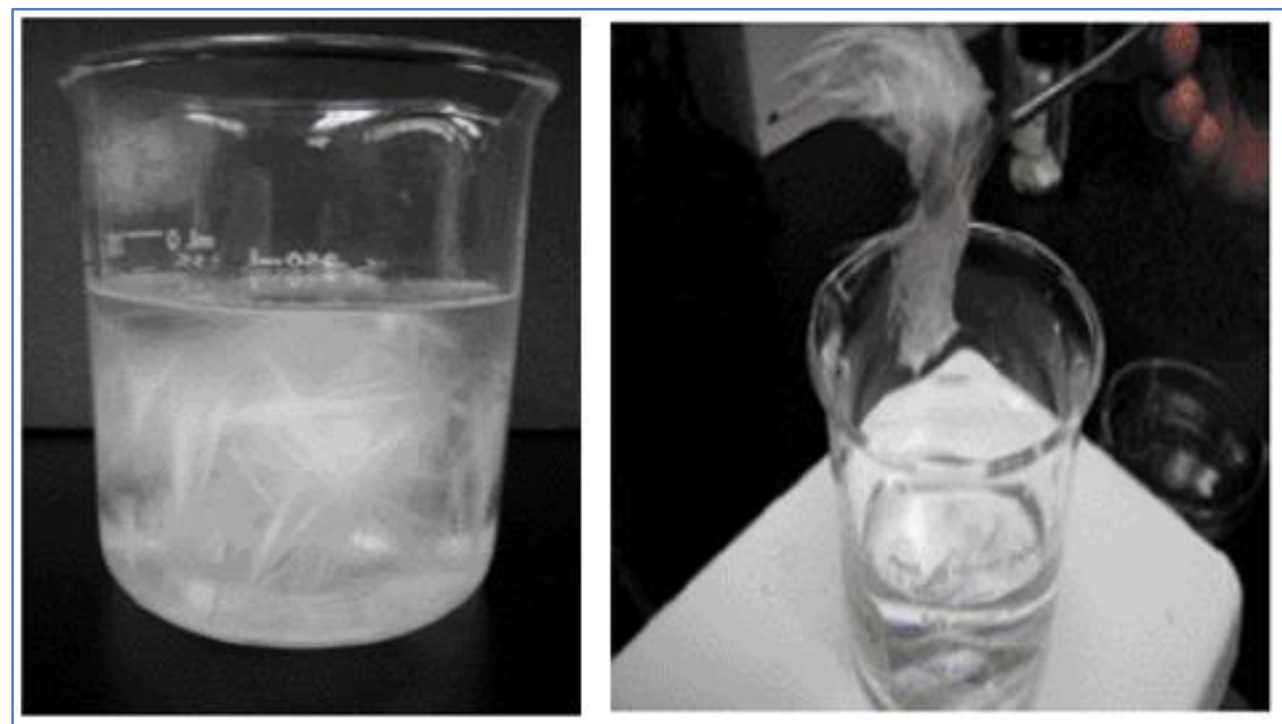

Fig. (2) Preparing Fiberglass to Mix with Cement Slurry. 


\section{Journal of Petroleum Research and Studies}

Open Access

No. 31, June 2021, pp.30-48

\subsection{Slurry Design:}

In order to obtain fitting cement slurry properties. The cement slurries were prepared according to the API standard. These properties are essential for getting cement slurry that is proper for oil well-cementing operations. With the aim of control, the local Iraqi cement performances, investigational tests were done on slurry. Experimental slurry quantities and their composition are shown in Table 2. The API Specifications 10A states the experimental procedure followed for preparing the different testers. These properties are as follows:

Table (2) Experimental Slurry Quantities and its Composition

\begin{tabular}{cccccc}
\hline Sample No. & $\begin{array}{c}\text { Mix water } \\
(\mathrm{ml})\end{array}$ & $\begin{array}{c}\text { Cement } \\
(\mathrm{g})\end{array}$ & $\begin{array}{c}\text { Fiberglass } \\
\text { BWOC\% }\end{array}$ & $\begin{array}{c}\text { Milled fiberglass } \\
\text { BWOC\% }\end{array}$ & $\begin{array}{c}\text { Superplasticizer } \\
(\mathrm{ml})\end{array}$ \\
\hline Sample 1 & 349 & 792 & 0 & 0 & 18 \\
Sample 2 & 349 & 792 & 0.125 & 0 & 18 \\
Sample 3 & 349 & 792 & 0.5 & 0 & 18 \\
Sample 4 & 349 & 792 & 0.75 & 0 & 18 \\
Sample 5 & 349 & 792 & 1 & 0 & 18 \\
Sample 6 & 349 & 792 & 2 & 0 & 18 \\
Sample 7 & 349 & 792 & 0 & 0.125 & 18 \\
Sample 8 & 349 & 792 & 0 & 0.5 & 18 \\
Sample 9 & 349 & 792 & 0 & 0.75 & 18 \\
Sample 10 & 349 & 792 & 0 & 1 & 18 \\
Sample 11 & 349 & 792 & 0 & 2 & \\
\hline
\end{tabular}

2.2.1 Free Water: Free fluid assessment for challenging cement slurries used to determine the slurry ability for preventing fluid separation at static conditions. Extreme free fluid in cement slurry may because many problems with water pockets, channeling, sedimentation, and zonal isolation. For the measurement of free water substances, the cement slurry is equipped and conditioned typically to API specifications at $80^{\circ} \mathrm{F}$ for 20 minutes. Subsequent cement slurry was remixed for an extra 35 seconds at high speed in a Waring blender. Next, the slurry's conditioning is emptied in a graduated cylinder and covered with aluminum to stop evaporation. Far along, it is subjected to 2 hours' test period. At the end of the investigation duration, a syringe was used for extracting 
free water that separated at the top of the slurry. Then the quantity of water is measured in milliliters (ml) [17].

2.2. 2Thickening Time: Thickening time point to the era within that cement slurry stay pump underneath well-simulated circumstances. The laboratory test situations should be representing the time, temperature, and pressure at which slurry will be exposed through pumping setups. Many factors may affect the slurry's pump facility during a job and cannot be simulated strictly through a test of thickening time: (fluid contamination, fluid loss to the formation, unforeseen temperature variations, and unexpected shutdowns in pumping). For determining the thickening time, the consistency of slurry is measured. The consistency, stated in Bearden units of consistency (B.C.), is determined by force executed by the slurry in contradiction of the paddle and dignified as a torque. The test is directed up to when the slurry reaches a consistency deemed sufficient for making it cannot be pumped (for instance, 70 or 100) Bc. The slurry consistency at which the thickening-time test was finished should be recognized and reported. The approval requirement for the extreme consistency for the duration of the 15 min to 30 min stirring era should be $30 \mathrm{Bc}$ for cement class $\mathrm{G}$. Thickening time test was run under 125 Find 5200 psi conditions. [18]

2.2.3 Compressive Strength: The compressive strength test governs cement slurry integrity and its capability to stand long period forced stresses. The curing time is 8 hours at $60^{\circ} \mathrm{C}$ and $38^{\circ} \mathrm{C}$ [19], as shown in Figure (3). 


\section{Journal of Petroleum Research and Studies}

Open Access

No. 31, June 2021, pp.30-48
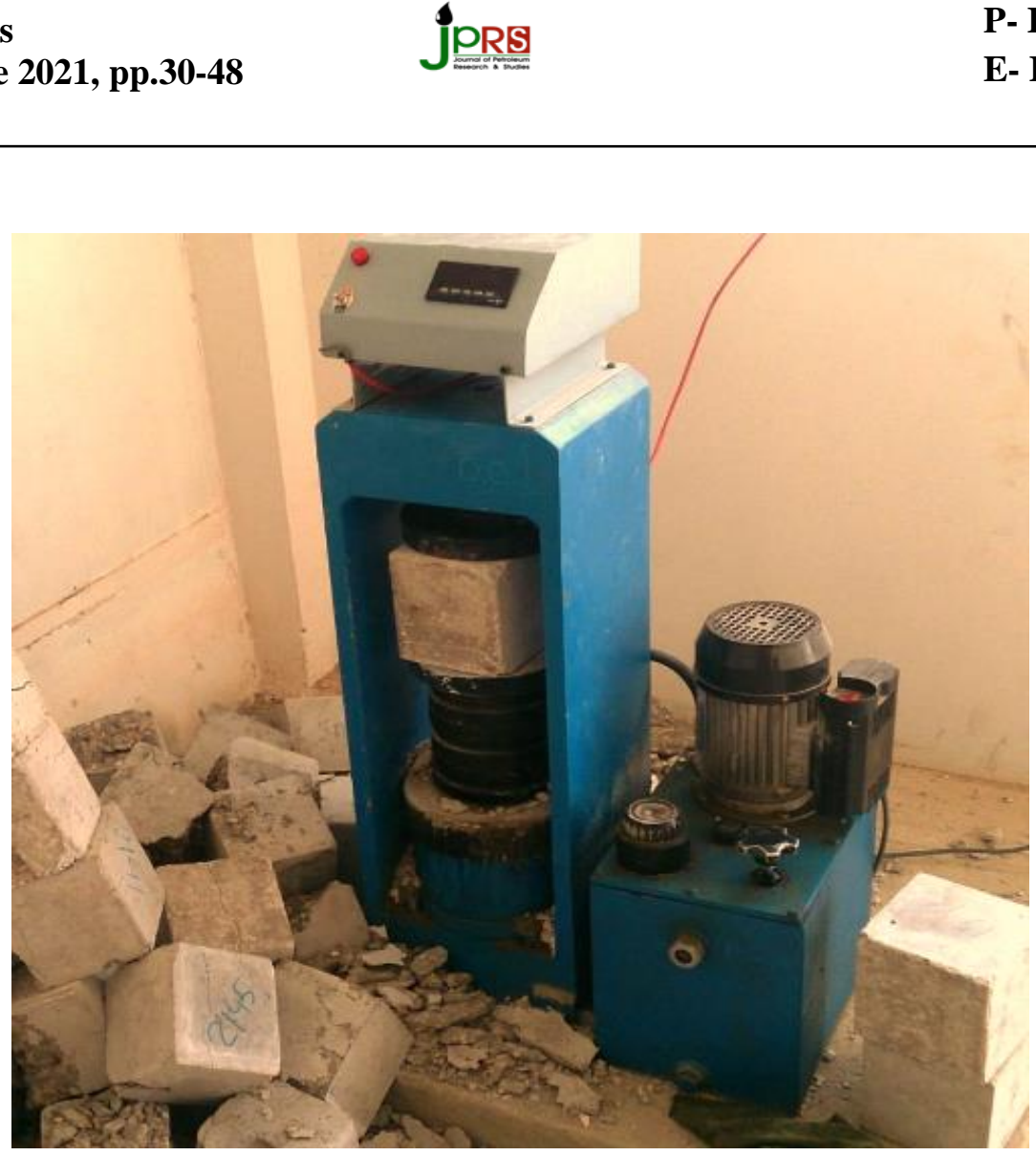

Fig. (3) Compressive Strength Test.

2.2.4 Rheology Test: The rheology influences slurry's performance and helps define the slurry's pump ability. At rheology test, flow properties: plastic viscosity and yield point of cement slurry are definite, using a rotational viscometer, for instance, HPHT Viscometer by Chandler at high-temperature conditions. Principally, the cement slurry is set and conditioned conferring to API specifications. The conditioned cement is emptied in a pre-heated cylinder of viscometer. Rheological parameters got by correlation of shear stress in contradiction of shear rate at the target temperature. The slurry rheology is tested at different temperatures, could be more than 2 , to use those data in hydraulic simulators, surface temperature, and downhole circulating temperature (simulated or from API tables) [18].600 rpm is not a portion of the process for testing the rheology of slurries. Eq. (1) and Eq. (2) were used to calculate the plastic viscosity and yield point of the cement slurry [19]. 


\section{Journal of Petroleum Research and Studies}

Open Access

No. 31, June 2021, pp.30-48

$\mu \mathrm{p}=1.5 *(\Theta 300-\Theta 100)$

$\mathrm{Yp}=\Theta 300-\mu \mathrm{p}$

Where:

$\mu$ p: plastic viscosity of the cement slurry.centi poise(cp)

Yp: yield point of the cement slurry $\left(\mathrm{lb} / 100 \mathrm{ft}^{2}\right)$.

$\Theta 300$ and, $\Theta 100$ : viscometer dial reading (rpm).

After recording the dial readings, divide the Up readings by the Down readings to get their ratio. If the ratio is other than $1: 1$, it can indicate the slurry may have settling or gelation problems. There may be settling problems if the readings are five numbers less for the down readings than for the up readings. Rheology is calculated by the correlation of shear stress against shear rate. Test data were obtained with Rotational Viscometer (different speeds): 300, 200, 100, 60, and $30 \mathrm{rpm}$.

2.2.5 Fluid Losses Test: This test is performed as per API recommended practice for testing well types of cement, API does not identify ranges to follow it, but in API 65, they reference that has to be low, $46 \mathrm{ml} / 30 \mathrm{~min}$ is a low value, usually used for production zones [17]. Table (2) illustrates the amount and concentration of the designed slurry.

2.2.6 X-ray Fluorescence Analysis (XRF): apparatus for elemental analysis and distribution imaging X-ray fluorescence analysis (XRF) uses characteristic X-rays (called "fluorescence X-rays") emitted under high-energy x-ray irradiation. XRF has some advantages that X-ray fluorescence analysis (XRF) provides useful elemental information about cement component, I s anon destructive analytical technique used to determine the elemental composition of materials. XRF determines the sample's chemistry by measuring the fluorescent X-rays emitted from the sample [18]. 


\section{Journal of Petroleum Research and Studies}

Open Access

No. 31, June 2021, pp.30-48

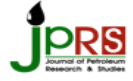

\section{Results and Discussion:}

The results of neat cement show that the compressive strength tests for Iraqi oil well cement class $\mathrm{G}$ at $38^{\circ} \mathrm{C}$ were excellent and acceptable according to the API standard specification $10 \mathrm{~A}$ (exceeded $300 \mathrm{psi}$ ), while the results at $60 \mathrm{C}^{\circ}$ are not satisfy compared to the API specification 10A (not exceeded $1500 \mathrm{psi}$ ). This can be attributed to the fact that the high-temperature curing can have a negative impact on early strength development. The essential observation is that adding less than $1 \%$ of synthetic fiber and $1 \%$ of milled glass fiber enhances the compressive strength and improves thickening, enhancing cement performance with fewer quantities and low cost than expensive materials. Figures (4) and (5) illustrate milled and glass fiber's effect on the value of the compressive strength of cement rock. Given that the above materials contain a high percentage of silica, the proportionality is proportional between the additives and the compressive strength up to less than $1 \%$ for glass fibers and less or equal to $1 \%$ for ground glass fibers was observed. It should be noted that the above materials' effect lies in the fact that they can bind the cement rock and not make it break.

The reason for the improvement in thickening time is attributed to the fact that the addition of synthetic fiber reduces the reaction of oil well cement at the early time of the hydration process and therefore increasing cement thickening time. Figure (6) illustrates the effect of adding glass and milled fiber materials on thickening time, and it can be said that the above two materials act as a retarder. Figure (7) shows the effect of adding glass and milled fibers on filtration and free water.

Regarding filtration, as shown in Figure (7) The two materials reduce the filtration value slightly when the additional percentage is less than $1 \%$ for the glass fibers and less than or equal to $1 \%$ for the grinded material. There is hardly a significant effect on the two inert materials on the value of free water. The reason is that the presence of these two substances slows down the cement slurry's hydration process. Figure (8) shows the effect of the two materials on the viscosity and yield point of the cement, 


\section{Journal of Petroleum Research and Studies}

Open Access

No. 31, June 2021, pp.30-48

where we notice a gradual increase in the above properties, then after that, there was a sudden increase and then a rapid decline, also it can be seen that the milled glass fibers gave higher values than those given by the glass fibers. Figure (9) shows the effect of adding the two materials on the density value of the cement slurry. It can be noticed that there is a slight increase in the density value when adding milled and glass fiber.

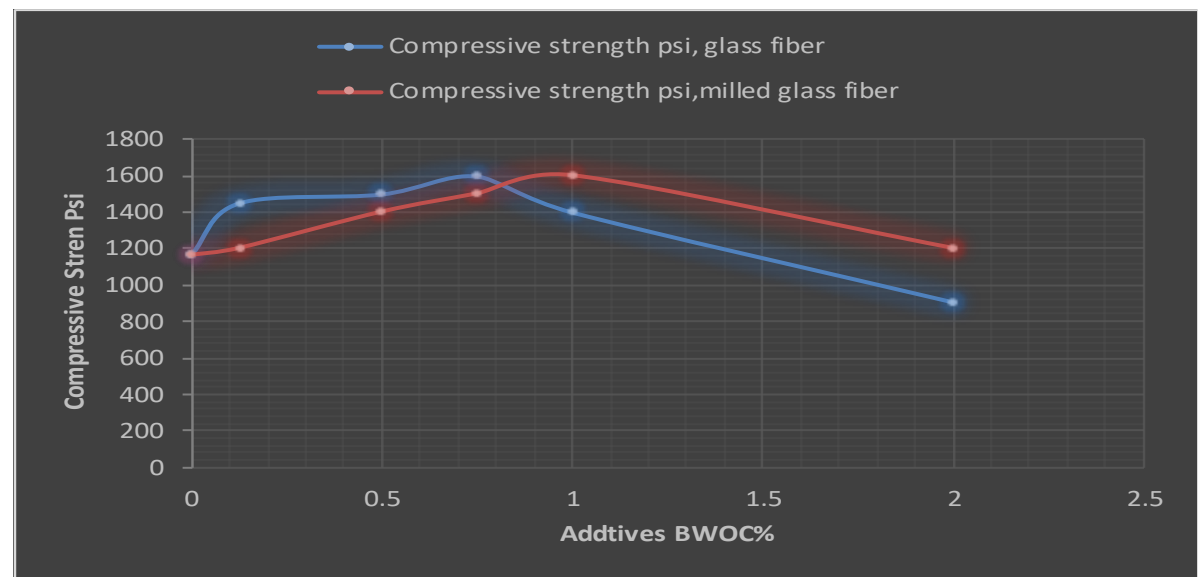

Fig. (4) The Effect of Glassfiber and Milled on Compressive Strength at 8 hrs $60^{\circ}$ C Curing

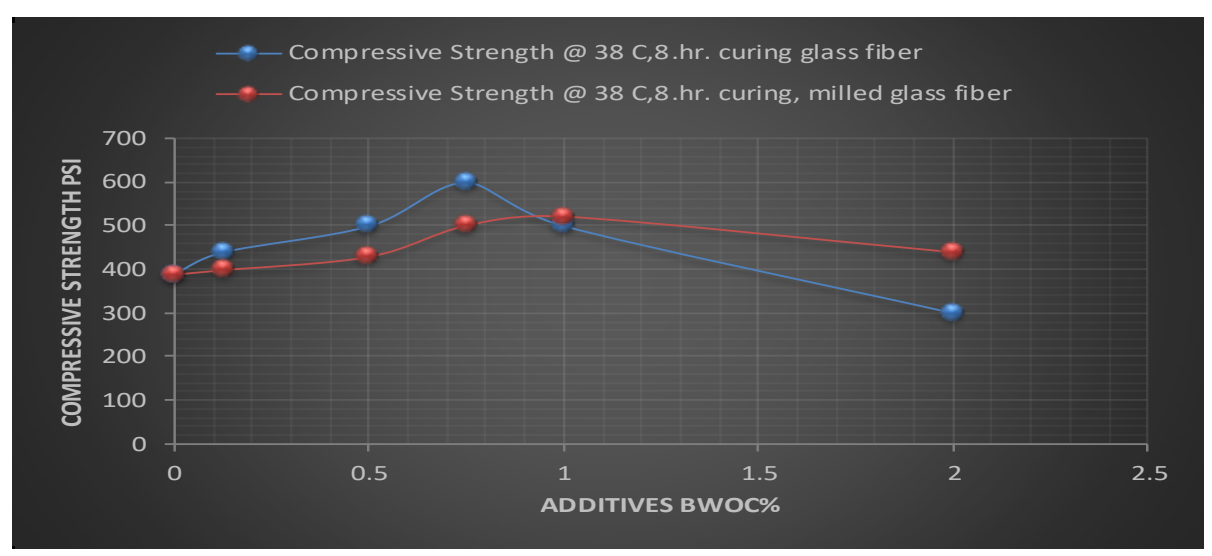

Fig. (5) The effect of Glassfiber and Milled on Compressive Strength at $38^{\circ} \mathrm{C}$ Curing 
Journal of Petroleum Research and Studies

Open Access

No. 31, June 2021, pp.30-48

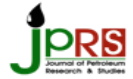

P- ISSN: 2220-5381

E- ISSN: 2710-1096

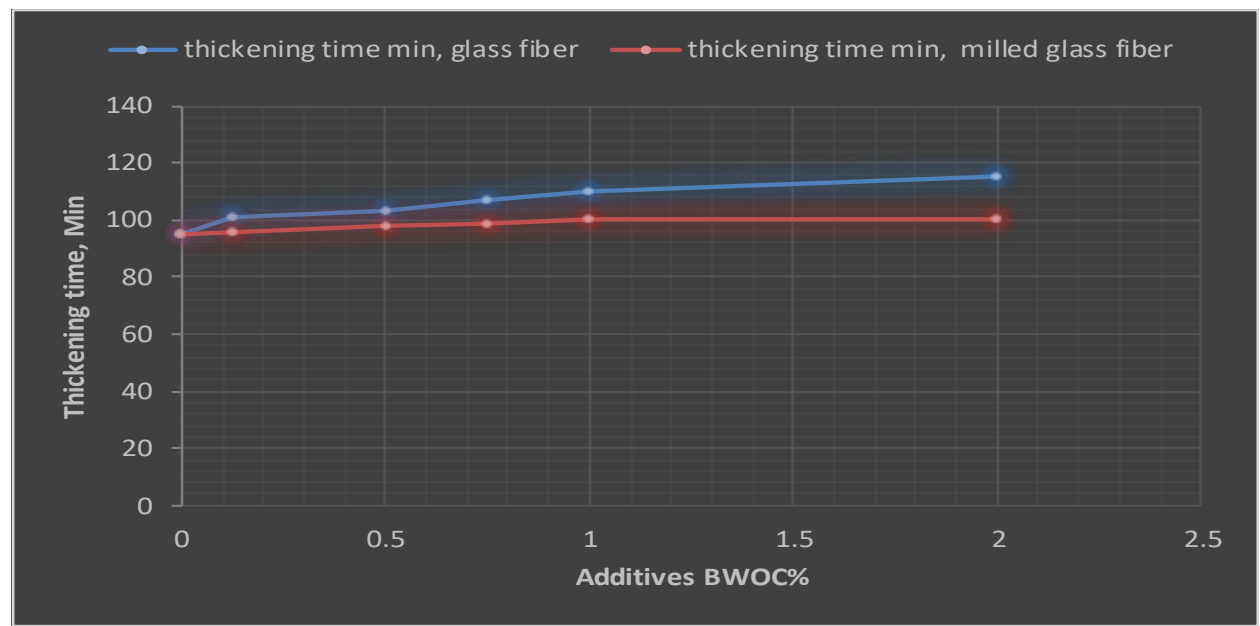

Fig. (6) The Effect of Glassfiber and Milled on Thickening Time at $125^{\circ} \mathrm{F}$ and 5200 psi.

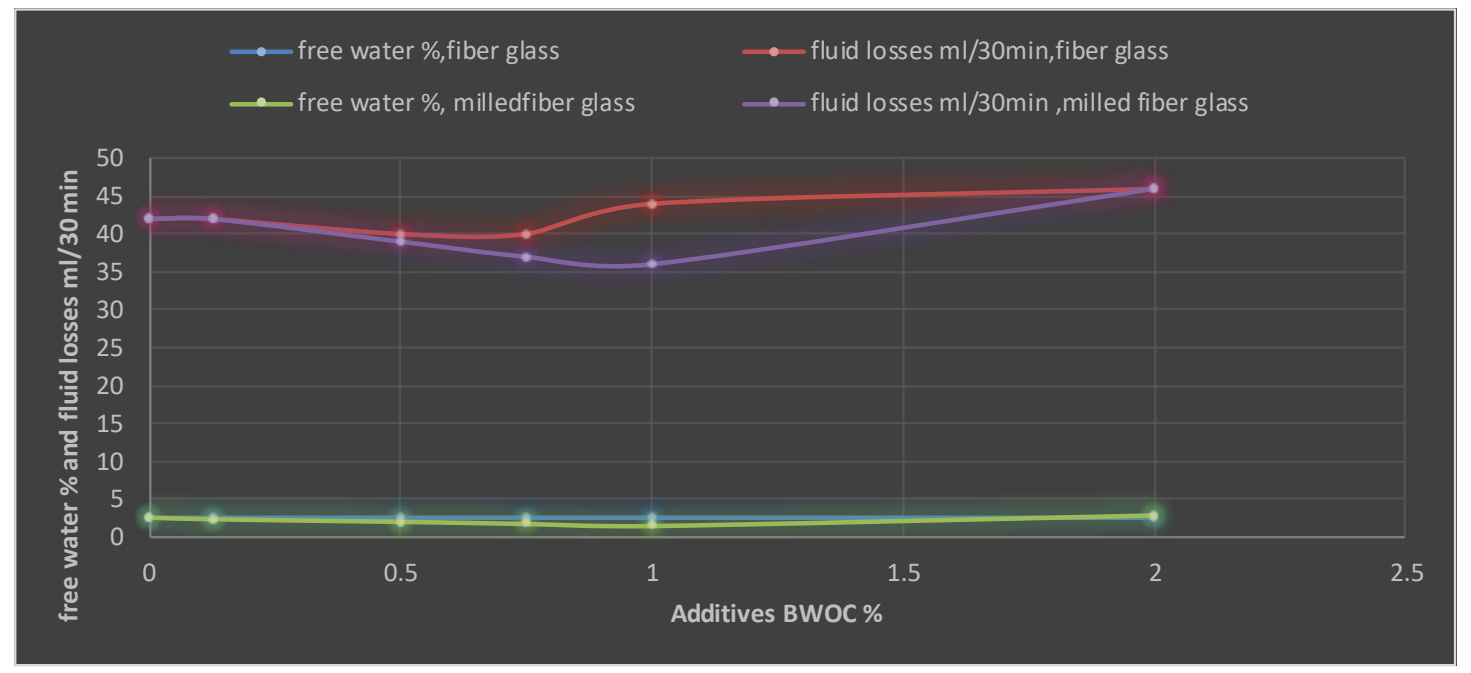

Fig. (7) The Effect of Glassfiber and Milled on Free Water and Filtration at $80^{\circ} \mathrm{F}$. 
Journal of Petroleum Research and Studies

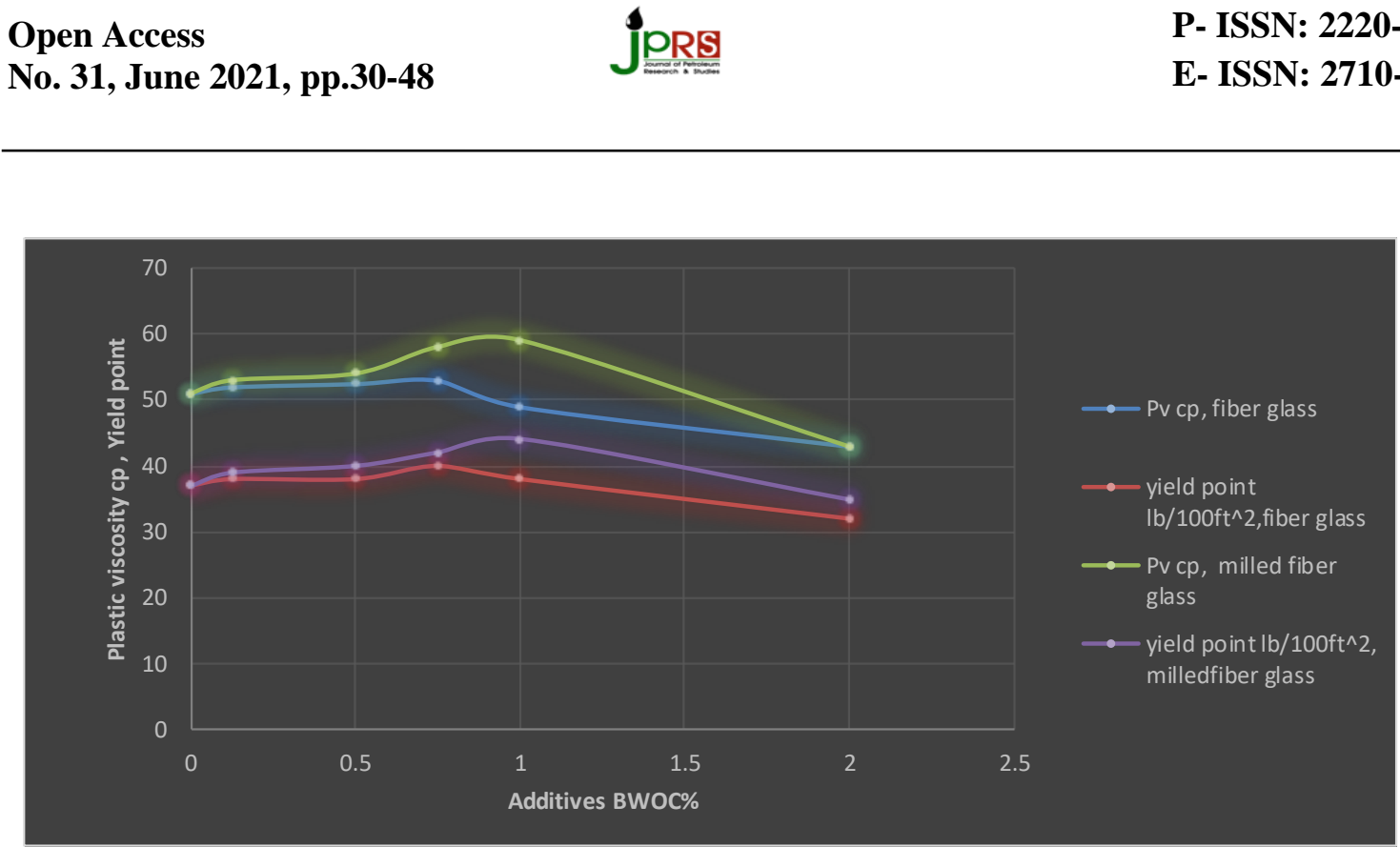

Fig. (8) The Effect of Glassfiber and Milled on Plastic Viscosity and Yield point

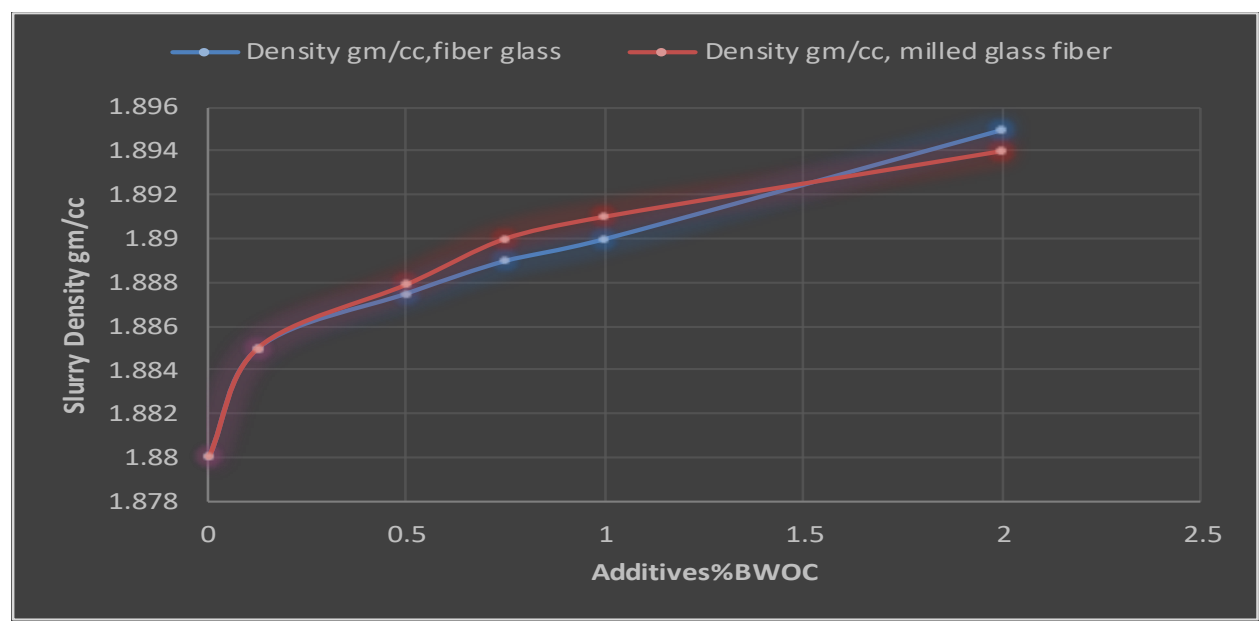

Fig. (9) The Effect of Glassfiber and Milled on Slurry Density

\section{Conclusions:}

By examining XRF, it was found that Iraqi cement contains a small percentage of silica, $18.63 \%$, compared to what the API requires of $24.66 \%$. The low percentage of silica material negatively affected the value of the cement rock's compressive strength, as the cement failed to test the compressive strength at 60 degrees Celsius. From that, silica- 


\section{Journal of Petroleum Research and Studies}

Open Access

No. 31, June 2021, pp.30-48

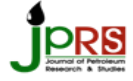

P- ISSN: 2220-5381

E- ISSN: 2710-1096

rich materials were used, such as glass and milled fibers, which led to an increase in the value of cement rock's compressive strength at 60 degrees. Adversely and negatively affect the value of compressive strength of the cement rock. The thickening time increase is considered one of the most important results obtained due to adding the two materials mentioned above. This enables us to deliver the cement slurry to the required place during the cementing process, especially when the production casing is cemented. As for the rest of the cement properties, such as (free water, filtration, viscosity, yield point), it is noticed that, the addition of glass fiber and milled have a slight effect on them, but the most extensive and vital effect was on the value of the compressive strength of the cement rock, which is highly required. Finally, it can be said that, the strength of glass fibers lies in the fact that they act as a bonding material for cement, thus they cause in increasing of the cement rock resistance. As for ground glass fibers, their strength lies in their small micron size, interacting with cement components and contributing to the increase in compressive strength.

\section{Abbreviations:}

A.R.G. Artificial Refined Glass

G.R.C. Glass fiber Reinforced Concrete

API American Petroleum Institute

ASTM American Society for Testing and Materials

Bc Bearden consistency

H.S.R High Sulfate Resistance

HPHT High-Pressure, High-Temperature

BWOC By Weight of Cement

XRF X-Ray Fluorescence Analysis

$\mu p \quad$ plastic viscosity of cement slurry

Yp yield point of cement slurry 


\section{Journal of Petroleum Research and Studies}

Open Access

No. 31, June 2021, pp.30-48

\section{References:}

[1] R. H. Jawad, "Flow of cement slurry through an eccentric annulus", Journal of Petroleum Research and Studies, vol. 10, no. 1, pp. 18-35, Mar. 2020.

[2] A. Bentur, S. Mindess, "Fibre reinforced cementitious composites", (Elsevier Science Publishers L.T.D., England, 1990).

[3] S. Kakooei, H. Md Akil, M.Jamshidi, J. Rouhi, "The Effects of Polypropylene Fibers on the Properties of Reinforced Concrete Structures", Construction and Building Materials Journal, , 27, 73-77, (2012).

[4] M. A. Mohamed, M. A.Moh, N. W. Akasha, I. Y. I. Elgady, "experimental study on effects of fiberglass and fiber waste in concrete mixes", International Journal of Engineering Science \& Research Technology, 3, 485-493, (2016).

[5] B. Graybeal A., F. Baby, "Development of Direct Tension Test Method for UltraHigh-Performance Fiber-Reinforced Concrete”, A.C.I. Materials Journal, 110, 177186, (2013).

[6] Hannant, D.J., "Fiber Cement and Fiber Concrete”, John Wiley and Sons Co., 1980.

[7] A.C.I. Committee 544, "State of the Art Report on Fiber Reinforced Concrete." (ACI 544.IR-82), Concrete International Journal, May 1982, P.P. 9-30.

[8] Fiber-Reinforced Concrete Title, Wikipedia. https://en.wikipedia.org/wiki/Fiberreinforced_concrete accessed on Aug. 8, 2019.

[9] R.H.O., Glass fiber. Journal of the Franklin Institute, (1943), 236(1): 80. https://doi.org/10.1016/S00160032(43)91201-3

[10] Fiberglass, https://en.wikipedia.org/wiki/Fiberglas accessed on Aug. 8, 2019.

Structural analysis of G.R.P. tank covers. Convention Composites.

[11] Lam, T.V., Bulgakov, B., Aleksandrova, O., Larsen, O., Ngoc Anh, P., "Effect of rice husk ash and fly ash on the compressive strength of high-performance concrete", E3S Web of Conferences, (2018).

https://doi.org/10.1051/e3sconf/20183302030 p.02030. 


\section{Journal of Petroleum Research and Studies}

Open Access

No. 31, June 2021, pp.30-48

[12] Subandi, Nasrulah, T., Arha, A.A., Zulkarnain, I., Asnan, M.N., "Effect of addition of rice husk charcoal on concrete compressive strength", International Journal of Engineering and Advanced Technology, 8(6): 4951-4955, (2019).

[13] Subandi, Kusuma, C., Asnan, M.N., Damaiyanti, M., Yatnikasari, S., Manufacture of concrete with artificial sand from rice husk waste. International Journal of Recent Technology and Engineering, 8(3): 1670-1673, (2019). https://doi.org/10.35940/ijrte.C4438.0983

[14] Afshinnia, K. and Rangaraju, P.R., "Effectiveness of Ground Glass Powder from Recycled Glass In Mitigating Alkali-Silica Reaction In Concrete", Transportation Research Record: The Journal of Transportation Research Board, Concrete Materials, Vol. 2508, p., 2015.

[15] Bismarck, A., Boccaccini, A.R., Egia-Ajuriagojeaskoa, E., Hülsenberg, D. and Leutbecher, T., "Surface characterization of glass fibers made from silicate waste: Zeta-potential and contact angle measurements", Journal of materials science, 39(2), pp.401-412, 2004.

[16] Chappex, T., and Scrivener, K.L., "The influence of aluminum on the dissolution of amorphous silica and its relation to alkali-silica reaction", Cement and Concrete Research, 42(12), pp.1645-1649, 2012.

[17] Collepardi, M., Monosi S., and Pauri, M., "The influence of superplasticizer type and dosage on the compressive strength of Portand cements concrete in the presence of fly ash", 1990.

[18] American Petroleum Institute (API), Specification 10A: Specification for Cements and Materials for Well Cementing. API/ANSI/ISO 10426-1. Washington, DC: American Petroleum Institute, 2002.

[19] L. Strüder, N. Meidinger, D. Stotter, J. Kemmer, P. Lechner, P. Leutenegger, H. Soltau, F. Eggert, M. Rhode, T. Schülein, High-resolution X-ray spectroscopy close to room temperature. Microsc. Microanal, 1999, 1(4): 622-631. 